\title{
Effect of Purified Trichoderma Reesei Cellulases on Formation of Cotton Powder from Cotton Fabric
}

\author{
Lea Heikinheimo, ${ }^{1}$ Arja Miettinen-Oinonen, ${ }^{1}$ Artur Cavaco-Paulo, ${ }^{2}$ Johanna Buchert ${ }^{1}$ \\ ${ }^{1}$ VTT Biotechnology, P.O. Box 1500, FIN-02044 VTT, Espoo, Finland \\ ${ }^{2}$ Dept. Textile Eng., University of Minho, P-4800 Guimarães, Portugal
}

Received 17 September 2002; accepted 26 February 2003

\begin{abstract}
The mode of action of monocomponent purified Trichoderma reesei cellobiohydrolases (CBHI and CBHII) and endoglucanases (EGI and EGII) on cotton fabrics was studied by analyzing the weight loss of the fabric, the reducing sugars, the soluble oligosaccharides and the molecular weight of the cotton powder formed. The impact of mechanical action on these factors was also evaluated. EGI and EGII released the highest amounts of reducing sugars and soluble oligosaccharides in both treatments with or without additional mechanical action. After cellulase treatment without additional mechanical action, all of the cellu-
\end{abstract}

lases were found to have reduced the molecular weight of cotton poplin powder. When mechanical action was combined with enzyme treatments, only EGII reduced the molecular weight. The weight loss of EG-treated fabrics was clearly higher than the weight loss of $\mathrm{CBH}$-treated fabrics with both low and high mechanical action levels. (C) 2003 Wiley Periodicals, Inc. J Appl Polym Sci 90: 1917-1922, 2003

Key words: enzymes; molecular weight distribution; fibers; high performance liquid chromatography (HPLC)

\section{INTRODUCTION}

Enzymatic hydrolysis of cotton cellulose has been studied in great detail since the 1980s, when enzymes were introduced to replace pumice stones in stonewashing cotton softening. ${ }^{1-3}$ Currently approximately $26 \%$ of all textile enzymes are used in biofinishing processes, and the total textile enzyme market is estimated to be worth about US\$ 200 million. ${ }^{4}$ Enzymatic finishing processes result in the reduction of production costs, increased environmental friendliness of the process, and improved quality and functionality of the products. However, some undesired effects of the enzymatic processes have also been reported.

Traditionally, cellulases used in the textile industry have been crude preparations. Producers of textile enzymes recommend cellulase preparation dosages of approximately 0.05 to $6 \%$ of the garment weight, depending on the desired result, the treatment method and the activity of the enzyme product. Enzymatic treatments are generally carried out with concomitant mechanical action in a drum washing machine or a jet. This mechanical action, together with unoptimized cellulase compositions and high enzyme dosages, may cause significant weight and strength losses in the cotton fabric. A suitable biofinishing effect without

Correspondence to: L. Heikinheimo, Lahti Polytechnic, Ståhlberginkatu 10, 15110 Lahti, Finland(lea.heikinheimo@ lamk.fi).

Journal of Applied Polymer Science, Vol. 90, 1917-1922 (2003) (C) 2003 Wiley Periodicals, Inc. excessive loss of fabric strength is generally obtained with $3-5 \%$ weight loss of fabric. ${ }^{5}$ In addition to weight and strength losses, dust also causes problems in the process. Repeated inhalation of enzyme-containing dust or mist can cause respiratory allergies in some individuals. ${ }^{6}$ The fine cotton dust formed in the biofinishing process can also cause problems for employees.

Trichoderma reesei cellulases are without question the most extensively studied of all cellulolytic enzymes, and the action of cellobiohydrolases (CBHs) and endoglucanases (EGs) has been evaluated against various textile substrates. ${ }^{7-14} \mathrm{CBH}$ cleave cellobiose units, either from the reducing or the non-reducing end of the cellulose chain, and they can act on crystalline regions of cellulose, whereas EGs randomly attack the amorphous regions in cellulose substrates, resulting in a rapid decrease in cellulose chain length. ${ }^{15}$ Many mechanistic studies of individual cellulases of $T$. reesei have focused on the analysis of soluble products formed from insoluble cellulose substrates and on the analysis of physical fabric properties such as weight loss, tensile strength and pilling. Furthermore, in several studies with $T$. reesei enzymes, the investigations have been carried out using commercial total cellulases (TCs), or possibly enriched or gene-deleted mixtures. ${ }^{7,13,16-18}$ Since dosage of the enzyme preparations is usually specified in grams or milliliters of enzyme preparation per gram of fabric, it is very difficult to make comparisons among different cellulase preparations and their effects on cotton fabrics.

The impact of cellulases on the molecular weight distribution of cellulose after enzyme attack has been 
investigated by Kleman-Leyer and associates, ${ }^{11}$ Azevedo and associates, ${ }^{16}$ Rouselle and associates, ${ }^{18}$ and Rahkamo and associates. ${ }^{19-20}$ Kleman-Leyer and associates $^{11}$ reported the changes in the molecular size distribution of insoluble cotton fragments after hydrolysis with Trichoderma reesei EGI cellulase. The weightaverage degree of polymerization $\left(\mathrm{DP}_{\mathrm{w}}\right)$ of the cellulose was reported to have decreased from 3,718 to 212 when the maximum weight loss of $35 \%$ was reached after $192 \mathrm{~h}$ of incubation, whereas CBHII did not affect the molecular size distribution of cotton cellulose. Similar results were obtained by Rahkamo and associates $^{19-20}$ using dissolving pulp as a substrate. On the other hand, Rousselle and associates ${ }^{18}$ did not observe any reduction in MW of cotton cellulose after three hours of treatment with total cellulase (Cellusoft L, Trichoderma origin) in a Launderometer despite the high weight loss $(20 \%)$ and breaking load reduction $(77 \%)$ of cotton printcloth fabric. In addition to investigations of substrate degree of polymerization (DP), the molecular weight of the cotton powder formed after treatment with different $T$. reesei cellulase preparations, or the total crude, EG-rich and $\mathrm{CBH}$-rich mixtures, was investigated by Azevedo and associates. ${ }^{16}$ They produced cotton powder (insoluble cellulose powder collected in liquor baths) from cotton poplin using a long treatment time $(24 \mathrm{~h})$, mechanical agitation and an enzyme dosage of $100 \mathrm{mg}$ protein per gram fabric. Their results showed that the EG-rich preparation reduced the DP more than the other preparations. However, the crude TC and CBH-rich preparations produced a finer cellulose powder than that produced by the EG-rich preparation.

The purpose of this study is to analyze the type and molecular weight distribution of the hydrolysis products obtained after the treatment of cotton poplin with monocomponent $T$. reesei EGI, EGII, CBHI and CBHII cellulases. The effect of mechanical action on cotton poplin hydrolysis is also evaluated.

\section{EXPERIMENTAL}

\section{Materials}

The cellulases CBHI, CBHII, EGI and EGII were purified from culture filtrate of $T$. reesei, as described previously by Pere and associates ${ }^{21}$ and Rahkamo and associates. ${ }^{19}$ Protein concentrations of the enzyme preparations were assayed by the method used by Lowry and associates. ${ }^{22}$

The fabric used for the enzyme treatments was commercially scoured and bleached plain woven $100 \%$ cotton poplin $(60$ ends $/ \mathrm{cm}, 32$ picks $/ \mathrm{cm}, 0.2 \mathrm{~mm}$ thickness, $100 \mathrm{~g} / \mathrm{m}^{2}$ weight). No optical brightener or softener was applied.

\section{Methods}

Enzymatic Treatments

For the enzyme treatment of woven poplin fabric, samples of about $2 \mathrm{~g}$ were placed in stainless steel pots $(500 \mathrm{~mL})$ in a Linitest machine for $4 \mathrm{~h}$ at $50^{\circ} \mathrm{C}$. The enzymatic treatments were carried out in $0.05 \mathrm{M}$ acetate buffer. With a $\mathrm{pH}$ of 5.0, at a liquor-to-fabric ratio of $25: 1$. The total enzyme dosage of purified cellulase was $10.0 \mathrm{mg}$ of protein per gram of substrate. Additional mechanical agitation was achieved by adding five stainless steel discs (of mass $20 \pm 2 \mathrm{~g}$, supplied with the Linitest machine) to the pots. Two duplicate tests were performed for each treatment. Reference treatments were carried out under the same conditions but without enzyme in the buffer solution. Termination of the enzyme reaction was achieved by adding $2.5 \mathrm{~mL}$ of $2 \% \mathrm{Na}_{2} \mathrm{CO}_{3}$ to the pots, after which the fabric samples were removed. The fabrics were rinsed in $5 \% \mathrm{Na}_{2} \mathrm{CO}_{3}$ solution $(1 \mathrm{~L})$ for about $1 \mathrm{~min}$ and rinsed under hot and cold water. Cotton powder was obtained after sedimentation and centrifugation from the liquid fraction remaining after enzyme treatment.

\section{Analyses}

Poplin fabric weight loss was measured as the difference in the weight of the fabric sample before and after treatment, after sample conditioning for $24 \mathrm{~h}$ at $20^{\circ} \mathrm{C}$ at $65 \%$ relative humidity. The degree of hydrolysis was monitored by measuring the amount of solubilized reducing sugars by the dinitrosalicylic acid method with glucose as a standard ${ }^{23}$ and by HPLC by measuring the solubilized oligosaccharides liberated. ${ }^{24}$ The molar mass distributions of cotton powder were determined using two PLgel Mixed-B columns and dimethylacetamide (DMAC) $/ 0.8 \% \mathrm{LiCl}$ as an eluent, at a flow rate of $1 \mathrm{~mL} / \mathrm{min}$ and a column temperature of $79^{\circ} \mathrm{C}$. Detection was with a Viscotek 200 differential refractometer/viscometer coupled in series with a Knauer UV detector measuring at $290 \mathrm{~nm}$. The columns were calibrated using monodisperse pullulan samples. The samples were dissolved in the eluent using a liquid exchange method described earlier by Westermark and associates. ${ }^{25}$

\section{RESULTS AND DISCUSSION}

Poplin fabric was treated with monocomponent $T$. reesei cellulases with a dosage of $10 \mathrm{mg} / \mathrm{g}$ fabric, after which the cotton powder formed was isolated and its molecular weight distribution was analyzed by GPC. In addition the soluble oligosaccharides formed in the treatment solution were analyzed by HPLC. 


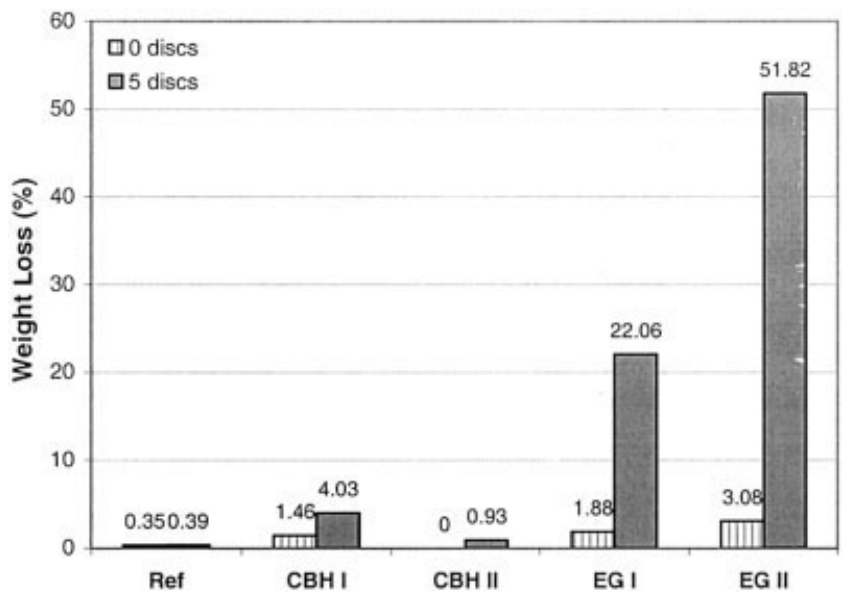

(a)

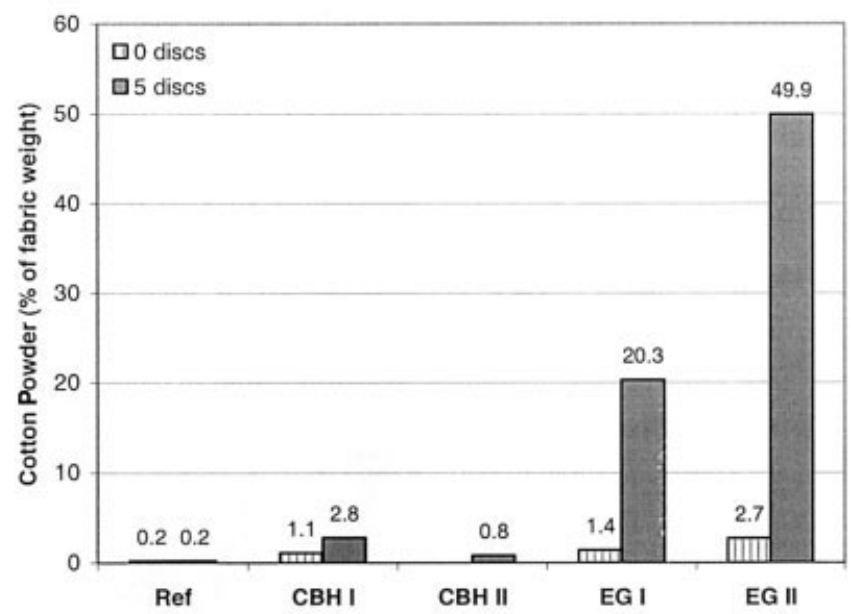

(b)

Figure 1 (A) Weight loss (\%) and (B) cotton powder formed (\% of fabric weight) from cotton poplin after treatment with purified cellulases CBHI, CBHII, EGI and EGII with low and high levels of mechanical action $\left(4 \mathrm{~h}, 50^{\circ} \mathrm{C}\right.$, enzyme dosage of $10 \mathrm{mg} / \mathrm{g}$ ).

\section{Treatment with Low Mechanical Action}

After cellulase treatments with low mechanical action, it was observed that weight loss and solubilization of the reducing sugars of the reference and CBHIItreated samples were negligible (Figs. 1 and 2). Treatment with EGI and EGII caused more weight loss than CBHI treatment, with values of $1.9,3.1$ and $1.5 \%$, respectively. The different modes of action of the cellobiohydrolases and endoglucanases (exo- and endoenzymes) were reflected in the oligosaccharides solubilized from the fabric (Table I). All cellulases solubilized cellobiose (G-2), whereas only EGII also solubilized cellotriose. The amount of larger oligosaccharides (cellotetraose and cellopentaose) was below the quantification limit. The results obtained from the HPLC measurements correlated well with our previous study of the action of $T$. reesei cellulases on cotton interlock fabric. ${ }^{10}$ The difference between weight loss and soluble reducing sugars was assumed to provide an estimate of the cotton powder produced during the treatment. With low mechanical action, the amount of cotton powder formed was less than $3 \%$ of the initial fabric weight [Fig. 1(b)].

The cotton powder was isolated and subsequently subjected to GPC analysis after solubilization in DMAC. A value of $85 \%$ of the cotton powder formed from the reference fabric could be solubilized, and this solubilization degree was increased to $93-100 \%$ after cellulase treatments (Table II). All cellulase treatments reduced the weight-average molecular weight $\left(M_{w}\right)$ of the cotton poplin powder, and the peaks of the molecular weight distribution curves were slightly shifted to a lower molecular weight compared to the powder produced in the reference treatment [Table II, Fig. (3)]. The value of $M_{w}$ was particularly sensitive to

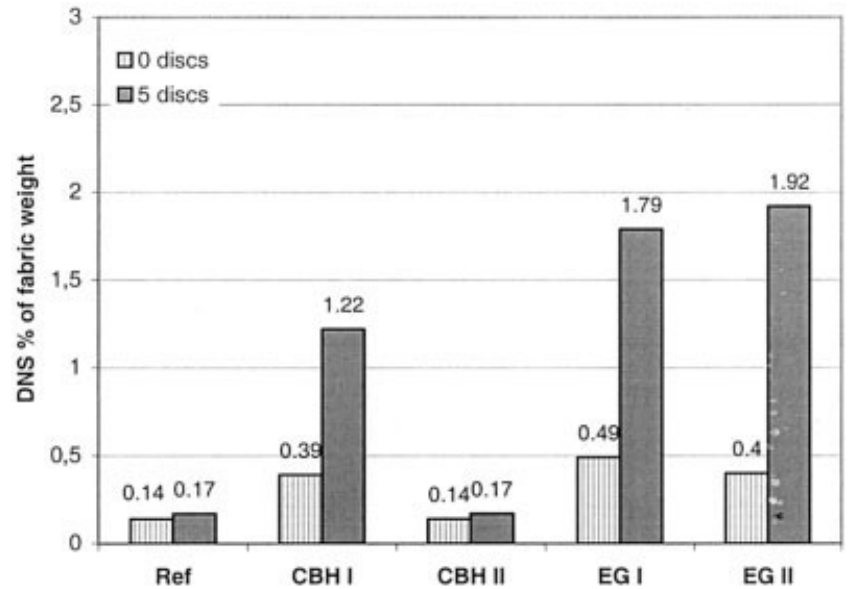

(a)

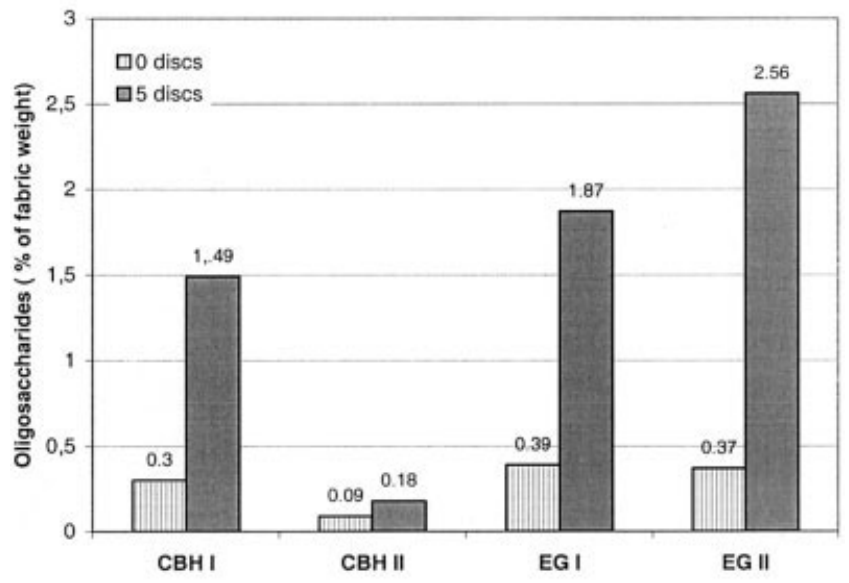

(b)

Figure 2 Liberation of (A) reducing sugars and (B) soluble oligosaccharides from cotton poplin with purified cellulases CBHI, CBHII, EGI and EGII with low and high levels of mechanical action $\left(4 \mathrm{~h}, 50^{\circ} \mathrm{C}\right.$, enzyme dosage of $\left.10 \mathrm{mg} / \mathrm{g}\right)$. Oligosaccharides are the sum of low-DP oligosaccharides as analyzed by HPLC. 
TABLE I

Oligosaccharide Production in Hydrolysis of Cotton Poplin by $T$. reesei Purified Cellulases

\begin{tabular}{|c|c|c|c|c|c|}
\hline Sample & $\begin{array}{l}\text { Mech. } \\
\text { Action }\end{array}$ & $\begin{array}{c}\text { Glc } \\
\text { (\% of f.w.) }\end{array}$ & $\begin{array}{c}\text { G-2 } \\
(\% \text { of } f . w .)\end{array}$ & $\begin{array}{c}\text { G-3 } \\
(\% \text { of } f . w .)\end{array}$ & $\begin{array}{c}\text { Total } \\
\text { (\% of } \mathrm{f.w} . \text { ) }\end{array}$ \\
\hline $\mathrm{CBHI}$ & - & $x$ & 0.30 & $x$ & 0.30 \\
\hline CBHII & - & $x$ & 0.08 & $x$ & 0.09 \\
\hline EGI & - & 0.11 & 0.28 & $x$ & 0.39 \\
\hline EGII & - & $x$ & 0.30 & 0.07 & 0.37 \\
\hline Ref & - & $x$ & $X$ & $x$ & - \\
\hline $\mathrm{CBHI}$ & + & 0.14 & 1.33 & 0.03 & 1.49 \\
\hline CBHII & + & 0.01 & 0.15 & 0.02 & 0.18 \\
\hline EGI & + & 0.55 & 1.28 & 0.04 & 1.87 \\
\hline EGII & + & 0.65 & 1.28 & 0.63 & 2.56 \\
\hline Ref & + & $x$ & $X$ & $x$ & - \\
\hline
\end{tabular}

Reaction conditions $-4 \mathrm{~h}, 50^{\circ} \mathrm{C}$, enzyme dosage of $10 \mathrm{mg} / \mathrm{g}$ with low or high mechanical action (5 discs added)

f.w. = fabric weight

$\mathrm{Glc}=$ glucose

$\mathrm{G}-2=$ cellobiose

G-3 = cellotriose

$\mathrm{x}=$ below quantification level

the presence of high-molecular weight species. The number-average MW $\left(M_{n}\right)$ was slightly increased after all cellulase treatments (Table II). This parameter is sensitive to species at the low end of the molecular weight distribution curve. Polydispersity $\left(P_{d}\right.$, the ratio of $M_{w}$ to $M_{n}$ ) was decreased by all cellulases, indicating narrower distribution curves.

\section{Treatment with High Mechanical Action}

Mechanical action did not have a significant effect on the weight loss and solubilization of reducing sugars in the control and CBHII treatments [Figs. (1) and (2)]. Weight loss in the CBHI treatment was increased from $1.5 \%$ to $4.0 \%$ by mechanical action. By contrast, mechanical action with EGI and EGII treatments resulted in high weight loss values, 22.1 and $51.8 \%$, respectively [Fig. (1)]. We obtained similar results earlier with purified $T$. reesei cellulases acting on cotton twill and poplin fabrics when high mechanical action was used. ${ }^{8}$ These results are analogous to observations by Cavaco-Paulo and associates ${ }^{17}$ on the same cotton poplin. They showed that the effect of endocellulases in the cellulase mixture increases with mechanical action. The data in Figures 1 and 2 show that the mechanical action affects hydrolysis by EGII more than by EGI, measured as weight loss and solubilization of reducing sugars.

HPLC analysis showed that the higher mechanical action increased the amount of solubilized oligosaccharide, especially when CBHI, EGI and EGII were used (Table I). The predominant hydrolysis product

TABLE II

Effect of Purified Cellulases and Mechanical Action on Molecular Weight of Cotton Poplin

\begin{tabular}{lccccc}
\hline Sample & $\begin{array}{c}\text { Mech. } \\
\text { Action }\end{array}$ & $\begin{array}{c}\text { Solubilization } \\
\%\end{array}$ & $\mathrm{M}_{\mathrm{n}}$ & $\begin{array}{c}\mathrm{M}_{\mathrm{w}} \\
(\times 1000)\end{array}$ & $\mathrm{M}_{\mathrm{w}} / \mathrm{M}_{\mathrm{n}}$ \\
\hline CBH I & - & 100 & 283,100 & 1,609 & 5.68 \\
& discs & 100 & 337,700 & 1,517 & 4.49 \\
CBH II & - & 93 & 349,500 & 1,756 & 5.02 \\
& discs & 84 & 313,000 & 1,561 & 4.98 \\
EG I & - & 100 & 292,100 & 1,716 & 5.87 \\
& discs & 100 & 280,600 & 1,544 & 5.50 \\
EG II & - & 100 & 288,600 & 1,716 & 5.94 \\
& Ref. & 100 & 218,000 & 1,347 & 6.18 \\
& - & 85 & 249,300 & 1,980 & 7.94 \\
& discs & 71 & 218,800 & 1,538 & 7.02 \\
\hline
\end{tabular}

Reaction conditions: $4 \mathrm{~h}, 50^{\circ} \mathrm{C}$, enzyme dosage of $10 \mathrm{mg} / \mathrm{g}$

$\mathrm{Mn}$ : number-average molecular weight

$\mathrm{M}_{\mathrm{W}}$ : weight-average molecular weight

$\mathrm{M}_{\mathrm{W}} / \mathrm{Mn}$ : polydispersity $\left(P_{d}\right)$ 
was again cellobiose and the amounts of longer oligosaccharides (cellotetraose and cellopentaose) were below the quantification limit. EGI and EGII also solubilized considerable amounts of glucose. Glucose is probably produced by the cellulases as a hydrolysis product from solubilized cello-oligomers. Glucose formation from cellotriose by EGI and EGII has been reported, ${ }^{26}$ and it has been shown that glucose is formed from cellotriose and cellotetraose by $\mathrm{CBHI}^{27}$ and from cellotriose by CBHII. ${ }^{28}$ Corresponding glucose formation from microcrystalline cellulose by $\mathrm{CBHI}$ and $\mathrm{EGII}^{29}$ and by $\mathrm{EGI}^{26}$ has also been reported.

Mechanical action increased the amount of cotton powder formed in the EGI and EGII treatments, whereas the impact was significantly less pronounced in the case of CBHI and CBHII [Fig. 1(b)]. As much as 20 and $50 \%$ of the fabric was converted to cotton power in the EGI and EGII treatments, respectively. The molecular weight distribution of the powder was subsequently analyzed. When the mechanical action was combined with enzymatic treatment, the differ-

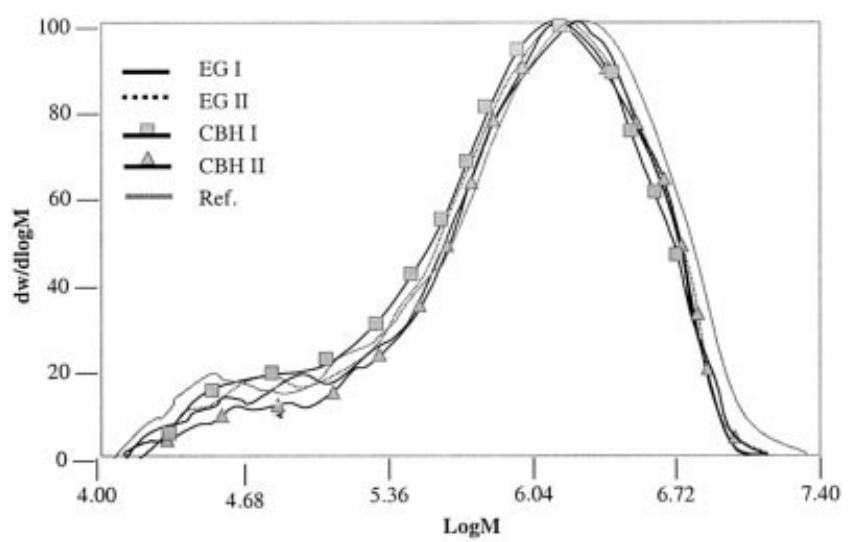

(a)

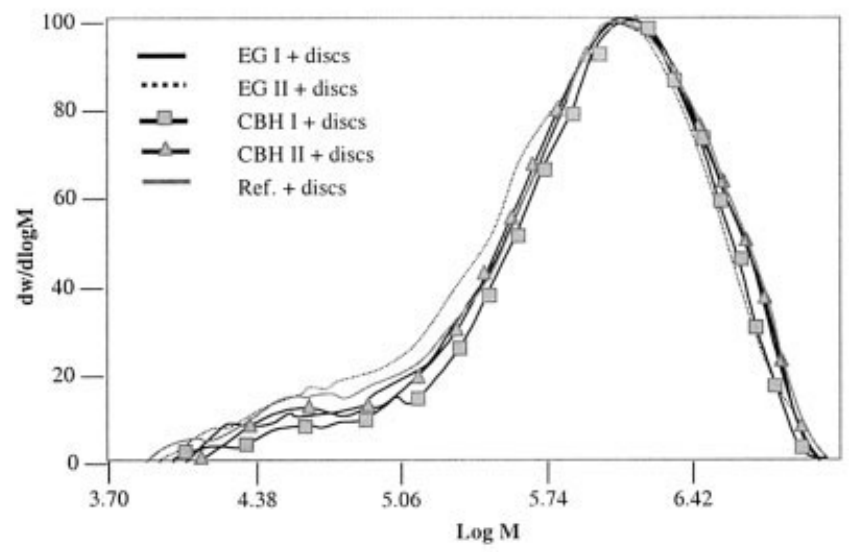

(b)

Figure 3 Molecular mass distribution of the cotton powder formed in T. reesei EGI, EGII, CBHI and CBHII treatment of cotton poplin fabric with (A) low or (B) high mechanical action $\left(4 \mathrm{~h}, 50^{\circ} \mathrm{C}\right.$, enzyme dosage of $\left.10 \mathrm{mg} / \mathrm{g}\right)$. Y-axis: weight change per logarithmic molar mass change.

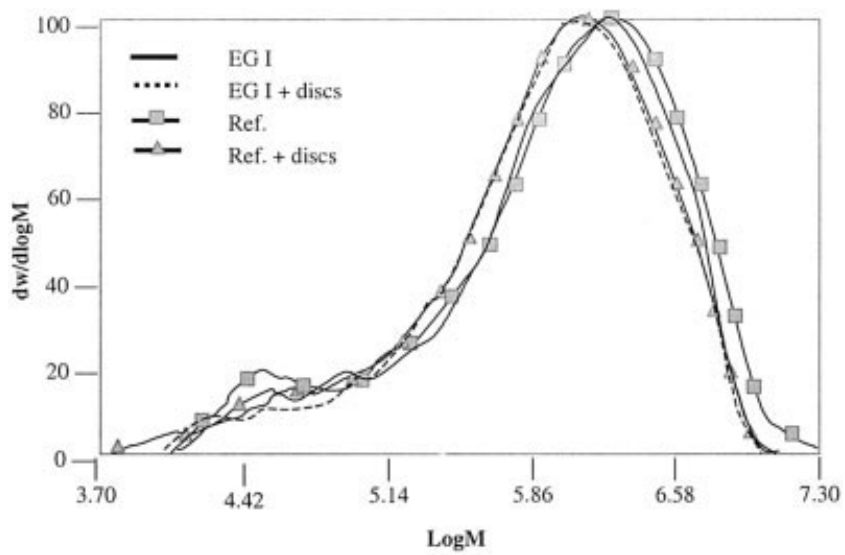

(a)

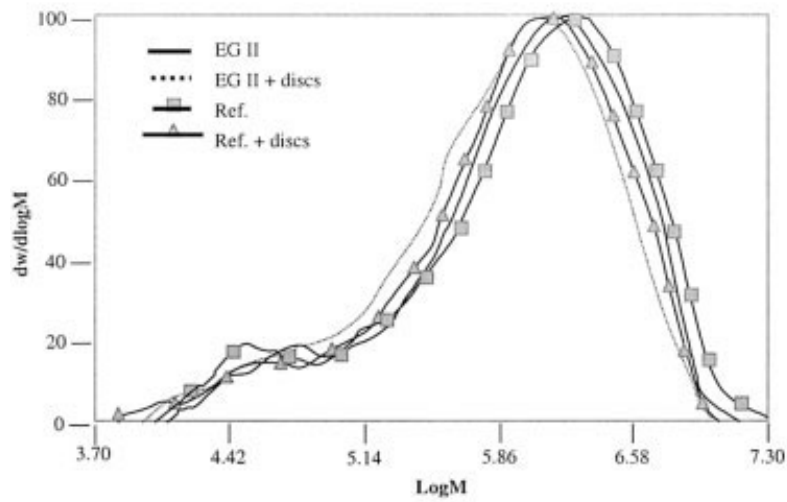

(b)

Figure 4 Effects of mechanical action on molecular mass distribution of cotton powder formed in T. reesei EGI, EGII and reference treatments of cotton poplin fabric $\left(4 \mathrm{~h}, 50^{\circ} \mathrm{C}\right.$, enzyme dosage of $10 \mathrm{mg} / \mathrm{g}$ ). Y-axis: weight change per logarithmic molar mass change.

ences among CBHI, EGI and CBHII treatments were diminished. Only in the case of EGII was a clear decrease in the molecular weight of cotton powder observed (Figs. 3 and 4). The DP of cotton may be as high as 14000 , but it can be easily reduced to 1000 2000 by different purification treatments with alkali. ${ }^{30}$ DPs of the cotton powders were estimated by calculating DP from the molecular weight of the powder. When low mechanical action was applied, the DP of the reference sample was 10990 and this was reduced to 9525 by EGII. Additional mechanical action reduced the DP of the reference sample to 8537 and of the EGII-treated sample to 7477. Mechanical action increased only the polydispersity of EGII-treated cotton powder, indicating a wider distribution. This is in agreement with other findings that the EGs cause more decrease of DP and molecular weight than the CBHs. ${ }^{13,16}$ Of the endoglucanases tested, EGII had the most pronounced effect on cotton.

Many studies have been carried out in order to improve understanding of the mechanism of cotton 
hydrolysis. Azevedo and associates ${ }^{16}$ reported that the insoluble material produced during enzymatic hydrolysis of cotton with high enzyme dosage $(100 \mathrm{mg} / \mathrm{g}$ fabric) presents a high specific surface area for cellulose adsorption. Furthermore, Cavaco-Paulo ${ }^{31}$ showed that adsorption of enzymes onto insoluble cellulose powders is about six to seven times higher than onto the cellulose of the main fabric structure. Thus, the produced powder is hydrolyzed faster than the original fabric. In short treatment times only the most accessible and external glycosidic bonds of fabrics are hydrolyzed leaving the molecular chain of cellulose intact (measured as MW), as shown by Rouselle and associates ${ }^{18}$ with total cellulase and by Morgado and associates ${ }^{13}$ with TC and EG-enriched enzymes. We did not measure the molecular weight distribution of the cellulose of the cotton fabric used as substrate in cellulase treatments. However, it can be expected that the effects would be in accordance with the findings of Rouselle and associates ${ }^{18}$ and Morgado and associates ${ }^{13}$ with short treatment time. EGs first attack the part of the substrate that is more exposed, such as pills or microfibrils at the fabric surface.

\section{CONCLUSIONS}

The purified cellulases EGI, EGII, CBHI and CBHII reduce the molecular weight of cotton powder formed during treatments of cotton poplin fabric when low mechanical action is used. However, with high mechanical action, EGII was the only enzyme that reduced the molecular weight of cotton powder. Mechanical abrasion has been indicated to cooperate synergistically with EG activity. ${ }^{17,32-33}$ According to our results, mechanical agitation affected EGII more than EGI when enzyme action was measured as weight loss of the fabric and as molecular weight of cotton powder. However, when the amount of solubilized oligosaccharides liberated was measured, there were no significant differences in the mode of action between EGI and EGII. CBHII did not cause any significant weight loss or solubilized oligosaccharides. Mechanical action had less a pronounced effect on CBHI treatments.

We thank Kati Uotila from VTT for expert technical assistance and Prof. Pertti Nousiainen from Tampere University of Technology and Matti Siika-aho from VTT for fruitful discussions. We are grateful to Bo Hortling from KCL for performing the GPC measurements. This research was financed by the Commission of the European Union ("Biofinishing of cotton with cellulases" BRPR-CT-95-0009).

\section{References}

1. Olson, L. American Dyestuff Reporter 1988, 19-22.

2. Kochavi, D.; Videbaek, T.; Cadroni, D. Reporter, 1990, 26-28.

3. Klahorst, S.; Kumar, A.; Mullins, M.M. Int. Conf. Exhib AATCC 1992, 243-249.

4. Ojapala, P. Textile Enzymes-Commercial Applications, In Proc. VTT Textile Research Seminar, Tampere, March 20; VTT: Espoo, Finland, 2002.

5. Lund., H.; Pedersen, H. Int. Pat. WO 96/17994 (1994).

6. Yingling, G. L. Textile Chem and Colorist \& Amer Dyestuff Reporter 2000, 32(1), 26-27.

7. Cavaco-Paulo, A.; Almeida, L.; Bishop, D. Textile Res J 1998, 68(4), 273-280.

8. Heikinheimo, L.; Cavaco-Paulo, A.; Nousiainen, P.; Siika-aho, M.; Buchert, J. JSDC 1998, 114, 18-22.

9. Heikinheimo, L.; Miettinen-Oinonen, A.; Suominen, P.; Buchert, J. Textile Res J 2000, 70(11), 969-973.

10. Heikinheimo, L.; Buchert, J. Textile Res J 2001, 71(8), 672-677.

11. Kleman-Leyer, K.; Siika-aho, M.; Teeri, T.; Kirk, T.K. Appl Environ Microbiol 1996, 62, 2883-2887.

12. Miettinen-Oinonen, A.; Heikinheimo, L.; Buchert, J.; Morgado, J.; Almeida, L.; Ojapalo, P.; Cavaco-Paulo, A. AATCC Review 2001, 33-35

13. Morgado J.; Cavaco-Paulo, A.; Rousselle, M. Textile Res J 2000, 70(8), 696-699.

14. Pere, J.; Puolakka, A.; Nousiainen, P.; Buchert, J. J Biotechnol 2001, 89(2-3), 247-255.

15. Chanzy, H.; Henrissat, B. FEBS Lett 1985, 184, 285-288.

16. Azevedo, H.; Ramos, L.; Cavaco-Paulo, A. Biotechnology Letters 2001, 23, 1145-1448.

17. Cavaco-Paulo, A.; Almeida, L.; Bishop, D. Textile Res J 1996, 66(5), 287-294.

18. Rousselle, M.; Howley, P. Text Res J 1998, 68(8), 606-610.

19. Rahkamo, L.; Siika-aho, M.; Vehviläinen, M.; Dolk, M.; Nousiainen, P.; Buchert, J. Cellulose 1996, 3, 153-163.

20. Rahkamo, L.; Viikari, L.; Buchert, J.; Paakkari, T.; Suortti, T. Cellulose 1998, 5, 1-10.

21. Pere, J.; Siika-aho, M.; Buchert, J.; Viikari, L. Tappi J 1995, 78(6), 71-78.

22. Lowry, O. H.; Rosenbrough, N. H.; Farr, A. R.; Randall, R. J. J Biol Chem 1952, 193, 265-275.

23. Miller, G. L. Anal Chem 1959, 31, 426-428.

24. Tenkanen, M.; Makkonen, M.; Perttula, M.; Viikari, L.; Teleman, A. J Biotechnol 1997, 55, 191-204.

25. Westermark, U.; Gustafsson, K. Holzforschung 1994, 48, 146150.

26. Karlsson, J.; Siika-aho, M.; Tenkanen, M.; Tjerneld, F. J Biotechnol 2002, 99, 63-78.

27. Harjunpää, V.; Helin, J.; Koivula A.; Siika-aho, M.; Drakenberg, T. FEBS Lett 1999, 443, 149-153.

28. Harjunpää, V.; Teleman, A.; Koivula A.; Ruohonen, L.; Teeri, T.; Teleman, O.; Drakenberg, T. Eur Biochem 1996, 240, 584-591.

29. Medve, J.; Karlsson, J.; Lee, D.; Tjerneld, F. Biotechnol Bioengin 1998, 59, 621-634.

30. Nevell, T. In Cellulose Dyeing; Shore, J., Ed.; Society of Dyers and Colourists: Manchester, UK, 1995; p 1-26.

31. Cavaco-Paulo, A. Carbohydrate Polymers 1998, 37, 273-277.

32. Azevedo, H.; Bishop, D.; Cavaco-Paulo, A. Enzyme and Microbial Technology 2000, 27, 325-329.

33. Cavaco-Paulo, A.; Almeida, L. Biocatalysis 1994, 10, 353-360. 